\title{
The Flame Characteristics of a Tyre Fire on a Mining Vehicle
}

\author{
Rickard Hansen ${ }^{1}[\mathbb{C}$
}

Received: 2 July 2021 / Accepted: 25 January 2022 / Published online: 10 February 2022

(C) The Author(s) 2022

\begin{abstract}
With vehicles frequently found in underground mines and tyres being a major fuel item, the risk of tyre fires will be severe underground. This study presents an in-depth analysis of tyre fires on mining vehicles to increase the knowledge of the risk, applying data from full-scale fire experiments and CFD simulations. It was found that the wheelhouse of the loader caused an increase in the flame tilt angle of approximately $10 \%$, decreasing the flame impingement and heat flux downstream. The flame temperature of the drilling rig tyre was found to be approximately $7 \%$ higher than the loader tyre, increasing the risk of igniting adjacent fuel items. The construction of the wheelhouse/mudguard will contribute to a longer flame length by creating a fuel-rich environment. The CFD simulations predicted higher flame tilt angles for the drilling rig case for higher flow velocities, indicating the influence of a varying wheelhouse/mudguard construction and tyre geometry on the flame tilt angle. The construction of the loader resulted in a flow behaviour, where the short distance to the front mudguard/tyre and the separation of flow directly downstream of the protruding construction led to fire gases being steered past the front mudguard/tyre. In the drilling rig case, the longer distance to the front mudguard/tyre led to fire gases being directed towards the body of the vehicle after passing the area with flow separation. An increased knowledge of the tyre fire risk on mining vehicles and mitigating measures would improve the fire safety in underground mines.
\end{abstract}

Keywords Flame $\cdot$ Underground mine $\cdot$ Tyre $\cdot$ Mining vehicle $\cdot$ Venturi effect $\cdot$ Wheelhouse $\cdot$ Mudguard $\cdot$ Longitudinal ventilation

\section{Introduction}

Vehicle fires - with vehicles being omnipresent in underground mines and constituting the dominant fire source [1, 2 ] - pose a severe risk in the mining industry. With the large dimensions of the mining vehicles comes a considerable size of the vehicle tyres, which could constitute a large portion of the fuel load. A tyre fire could lead to extensive smoke production and a difficult fire suppression operation. A high priority in the fire safety work would thus be to prevent the ignition of a tyre and mitigate the consequences of a tyre fire on a mining vehicle. One of the key tools during this work would be the construction of the vehicle, the wheelhouse, the mudguard and the distance to adjacent fuel items to be more precise. An earlier study on the role of the passive fire protection [3] pointed out measures taken

Rickard Hansen

rickard.hansen@uq.edu.au

1 Sustainable Minerals Institute, The University of Queensland, Brisbane, QLD 4072, Australia at the wheelhouse to reduce the risk of ignition and further fire spread.

This paper looks further into the flame behaviour of the tyre fire in a mine drift, primarily influenced by the longitudinal ventilation flow and the surrounding wheelhouse or mudguard. Discussions on wheelhouse and mudguard design are presented to prevent ignition and mitigate effects of an occurring tyre fire. Data from full-scale fire experiments and CFD simulations were applied in the work.

The purpose of this paper is to investigate issues such as the effect of the wheelhouse or mudguard on the flame behaviour, the behaviour of the flames outside the wheelhouse and mudguard and designs of the vehicle to mitigate the effects of a fire.

Earlier works on fire behaviour in underground mines or tunnels with longitudinal ventilation have mainly focused on critical ventilation velocity and backlayering length. Few studies can be found on obstacles or constructions influencing the flame behaviour, flame tilt, or flame lengths in mines or tunnels. Most fire plume and flame studies have been on flame behaviour of open fires in tunnels, obstacles 
influencing the critical ventilation velocity or the interaction between a fire plume and an inclined surface.

Earlier studies on the flame base extent due to longitudinal ventilation flow have been conducted by Welker et al. [4], Moorhouse [5] and Johnson [6], where experiments with pool fires were used to study the influence of the ventilation flow, size of burner and type of fuel. The influence of vehicle blockage on the smoke behaviour in tunnels has been the focus of several studies. Oka and Atkinson [7] and Lee and Tsai [8] performed model-scale experiments and numerical simulations to study the influence of vehicle blockage on the critical ventilation velocity. Chaabat et al. [9] performed several experiments in a model-scale tunnel, investigating the impact of solid barriers on the backlayering length and the critical ventilation velocity. Wu et al. [10] studied the interaction between a fire plume and an inclined surface, using a gas burner as a fire source during the experiments. Isothermal as well as adiabatic surfaces with inclination angles ranging from $0^{\circ}$ to $40^{\circ}$ were used in the experiments. It was found that the fire plume bent towards the surface, with a distinct increase in the attachment length along the inclined surface when the inclination angle reached $24^{\circ}$. This is in line with earlier experiments by Smith [11] and Wu and Drysdale [12], which resulted in critical inclination angles ranging from $24^{\circ}$ to $27^{\circ}$. Kurioka et al. [13] performed fire experiments in model-scale and full-scale tunnels to investigate the influence of the crosssection, heat release rate and ventilation velocity on the following near field parameters: flame tilt, apparent flame height, maximum temperature of the smoke layer and its position. Oka et al. [14] conducted fire experiments to analyse the effects of cross-wind on flame properties for unconfined fires. Oka and Kurioka [15] conducted fire experiments to investigate the effects of the fire source shape and size on the flame tilt angle, maximum temperature rise of the smoke layer near the ceiling and its position. Li and Ingason [16] developed flame tilt angle relationships for tunnel fires with a longitudinal ventilation flow present. Data from model-scale and full-scale fire experiments were applied during the analysis. Rew and Deaves [17] presented a study on the fire spread and flame lengths of tunnel fires with longitudinal ventilation, resulting in a flame length correlation containing heat release rate and the ventilation flow velocity. Ingason and $\mathrm{Li}$ [18] performed fire experiments in a model-scale tunnel and the study resulted in a flame length correlation which was validated against full-scale tunnel fire experiments. Hansen [19] performed fire experiments in a model-scale mine drift involving several individual fire sources and developed a correlation for the continuous flame length of multiple fire sources. Earlier studies on fire protection measures of wheelhouses have been limited to studies by Johnsson and Yang [20] and Hansen [3]. Johnsson and Yang [20] studied the fire spread from a tyre fire into a motorcoach passenger compartment, focusing on possible fire spread paths and mitigating measures. Hansen [3] analysed the risk of tyre fires and suggested passive fire measures to be taken at and in the vicinity of the wheelhouse.

Few studies have been conducted on the fire behaviour of tyre fires. Wraight [21] conducted fire experiments on samples of rubber cut from a tyre to investigate the fire behaviour and ignitability of the tyre samples. Shipp and Guy [22] performed large-scale fire experiments on stacked tyres, measuring the heat release rate of vertically and horizontally stacked passenger vehicle tyres without steel rims. Hansen [23] and Ingason and Hammarström [24] conducted fire experiments on free standing truck tyres and loader tyres, measuring the heat release rates of the tyres.

A further in-depth analysis of the tyre fires on mining vehicles and possible mitigating measures will increase the fire safety in the mining industry.

\section{Flame Behaviour in a Mine Drift}

Two key characteristics of flame behaviour are the flame length and the flame tilt angle. The flame length is highly dependent on the heat release rate which in turn will depend on the entrainment rate, where an increased entrainment rate will increase the rate of reaction and thus shorten the reaction zone and the flame length. Any constraints on the entrainment - such as physical obstructions blocking or reducing the air flow - will lead to longer flame lengths. Flames from a fire may be deflected and tilted due to an occurring wind or an existing longitudinal ventilation flow. The extent of the flame tilt will largely depend on the wind/ventilation velocity and the heat release rate of the fire.

Flames occurring in a mine drift will be greatly affected by the longitudinal flow from the mechanical ventilation system. A longitudinal ventilation flow can be expected throughout the entire underground mine. The ventilation flow will tilt the flames in the same direction, but also provide an effective supply of oxygen to the fire site, which will increase the entrainment rate and shorten the flame lengths. $\mathrm{Li}$ and Ingason studied tunnel fires with longitudinal ventilation flow and developed the following flame tilt angle relationships (the fire sources were free burning fires with no barriers or blockages present in tunnels) [16]:

$\sin \phi=1 V^{\prime} \leq 0.19$

$\sin \phi=\left(5.26 \bullet V^{\prime}\right)^{-0.6} \quad V^{\prime}>0.19 \quad \dot{Q}^{*} \leq 0.15$

$\sin \phi=0.25 \cdot\left(\frac{D}{2} \cdot \frac{V^{* 3}}{H}\right)^{-0.2} \quad V^{\prime}>0.19 \quad \dot{Q}^{*}>0.15$

$V^{\prime}=\frac{u}{w^{*}}$ 
$\dot{Q}^{*}=\frac{\dot{Q}}{\rho_{a} \cdot c_{p} \cdot T_{a} \cdot \sqrt{g} \cdot H_{f}^{5 / 2}}$

$w^{*}=\left(\frac{g \cdot \dot{Q}}{\frac{D}{2} \cdot \rho_{a} \cdot c_{p} \cdot T_{a}}\right)^{1 / 3}$

$\mathrm{V}^{*}=\frac{\mathrm{u}}{\sqrt{\mathrm{g} \cdot \mathrm{H}}}$

where $\phi$ is the flame tilt angle (degrees) (i.e. the angle between the horizontal and the line connecting the fire source centre and the position of maximum temperature), $V^{\prime}$ is the dimensionless ventilation velocity, $\dot{Q}^{*}$ is the dimensionless heat release rate, $\dot{Q}$ is the heat release rate $(\mathrm{kW}), H$ is the mine drift height $(\mathrm{m}), H_{f}$ is the height from the fire source centre to the mine drift ceiling (m), $D$ is the diameter of the fire (m), $V^{*}$ is the dimensionless longitudinal velocity, $u$ is the longitudinal velocity $(\mathrm{m} / \mathrm{s}), w^{*}$ is the characteristic plume velocity, $\rho_{a}$ is the density of the ambient air $\left(\mathrm{kg} / \mathrm{m}^{3}\right), c_{p}$ is the heat capacity $(\mathrm{kJ} / \mathrm{kg} \mathrm{K})$ and $T_{a}$ is the temperature of the ambient air (K). Equation (4) contains both the forced longitudinal ventilation velocity and the characteristic plume velocity, where the latter will relate to the buoyancy force of the fire plume and the heat release rate of the fire. Thus, Eq. (4) contains the two forces, which will be decisive with respect to the flame tilt angle.

Kurioka et al. [13] developed the following flame tilt angle based on model-scale and full-scale tunnel fire experiments (the fire sources were free burning fires with no barriers or blockages present in tunnel):

$\cos \theta=\alpha \cdot\left[A_{f}^{1 / 2} \cdot \frac{b^{1 / 2}}{H^{3 / 2}} \cdot \dot{Q}^{*\left(1-\frac{2 \bullet \eta}{5}\right)} \cdot F r^{-1 / 2}\right]^{\beta}$

$F r=\frac{u^{2}}{g \cdot H_{f}}$

where $\theta$ is the angle between the horizontal and the plume axis (degrees), $\alpha$ and $\beta$ are experimental constants, $A_{f}$ is the area of the fire source $\left(\mathrm{m}^{2}\right), b$ is the mine drift width (m), $\eta$ is a coefficient determined in each region (the fire plume is divided into three regions depending on the maximum temperature of smoke layer beneath the ceiling) and $\mathrm{Fr}$ is the dimensionless Froude number. Same as for Eq. (4), Eqs. (8) and (9) contain parameters relating to the forced longitudinal ventilation flow $(u)$ and the buoyancy force $\left(\dot{Q}^{*}\right)$.

The cross-sectional dimensions of the mine drift will affect the flame length; a mine drift with a larger crosssectional area will contain larger air masses and will result in shorter flame lengths compared with a mine drift with much smaller dimensions.
The distance between the fire source centre and the mine drift ceiling will also affect the flame length; with an increasing distance, the flame length will decrease. Flame length correlations that were developed by Ingason and $\mathrm{Li}$ [18] have been found to match flame lengths from full-scale fire experiments in a mine:

$L_{f}=4.3 \cdot H \cdot \dot{Q}_{f}^{*}$

$\dot{Q}_{f}^{*}=\frac{\dot{Q}}{\rho_{a} \cdot c_{p} \cdot T_{a} \cdot g^{0.5} \cdot A \cdot H_{f}^{0.5}}$

where $L_{f}$ is the flame length (m), $\dot{Q}_{f}^{*}$ is the dimensionless heat release rate and $A$ is the cross-sectional area of the mine drift $\left(\mathrm{m}^{2}\right)$. Equations (10) and (11) contain parameters describing the cross-sectional dimensions of the mine drift as well as the distance between the fire source centre and the mine drift ceiling. The equations do not include any longitudinal ventilation velocity parameter as Ingason and $\mathrm{Li}$ [18] in their analysis found that the flame length was only a weak function of the longitudinal ventilation flow.

Rew and Deaves [17] studied the fire spread and flame lengths of tunnel fires with longitudinal ventilation and presented the following flame length correlation:

$L_{f}=20 \cdot\left(\frac{\dot{Q}}{120}\right) \cdot\left(\frac{u}{10}\right)^{-0.4}$

As opposed to the correlations by Ingason and $\mathrm{Li}$ [18], the flame length correlation by Rew and Deaves [17] does not contain any parameters related to the geometrical aspects of the mine drift or the distance between the fire source centre and the mine drift ceiling. Instead, Eq. (12) contains the longitudinal ventilation flow velocity. The flame length correlations of Ingason and Li [18], and Rew and Deaves [17] were earlier found to come close to observed flame lengths from full-scale fire experiments in a mine drift [25].

\section{Tyre Fires and the Wheelhouse and the Mudguard}

Vehicle fires generally constitute most of the fires in underground mines and will be found in most parts of a mine due to the system of ramps and drifts accessible to the vehicles. Besides the high frequency of mining vehicle fires, the generally high fuel load of the vehicles will further add to the risks and where the considerable size of the tyres will constitute a large part. A tyre will have a higher critical heat flux compared to most outer layers on electrical cables and hydraulic hoses and will therefore not ignite as easily. But if ignition occurs, the resulting fire will be distinguished by the considerable smoke production, a high heat release rate 
and difficulty to suppress. A tyre fire will also be distinguished as a surface fire, where the flame spread will take place along the tyre surface and determine the heat release rate. The longitudinal ventilation flow will have a large impact on this surface fire spread, as the ventilation flow may either enhance or diminish the flame spread depending on the direction of the ventilation flow in relation to the tyre surface orientation. The threads along the tyre surface will to a certain degree affect the fire behaviour of the tyre. The voids of the thread may contain a fuel-rich environment, which will increase the maximum heat release rate if the ventilation flow velocity is increased.

A mining vehicle in a mine drift is assumed to be most likely positioned parallel or nearly parallel with the longitudinal ventilation flow direction. This assumption applies throughout the entire study.

The wheelhouse and the mudguard will have several different impacts on the tyre fire behaviour. The wheelhouse and the mudguard may block the ventilation flow, reduce the entrainment rate and affect the flame tilt and the flame length. The wheelhouse, the mudguard and the body of the vehicle may direct the ventilation flow in the near vicinity in a certain direction, which may cause a change in the flame spread. The flame spread may decrease due to the reduction in the entrainment rate, but the wheelhouse or the mudguard construction may also enhance the thermal feedback - i.e. the radiative and convective heat transfer from the flames and fire gases - back to the fuel surface and increase the flame spread and heat release rate. Intuitively, the wheelhouse and the mudguard construction should cause an increase in the flame spread at the early phases of the fire as the environment enclosed by the wheelhouse, or the mudguard will be fuel controlled at the early phases.

The positioning of a mining vehicle in a mine drift will cause a Venturi effect; i.e. the mining vehicle will act as a barrier to the ventilation flow and cause an acceleration of the ventilation flow due to the reduction in the crosssectional area (principle of mass continuity). The Venturi effect may therefore increase the entrainment rate and the heat release rate of the fire, which in turn will affect the flame tilt angle and flame length.

The Venturi effect will also cause a reduction in the static pressure along the side of the vehicle (conservation of mechanical energy). This pressure reduction will cause an ejection of the emitted fire gases from the burning tyre, and increase the mixing of the flowing air and the emitted fire gases, further increasing the entrainment rate.

The flowing air underneath the vehicle will encounter the burning tyre and be drawn into the wheelhouse or the mudguard, causing a chimney effect due to the thermal difference between the air flowing into the wheelhouse or the mudguard and the emitted fire gases at the upper part of the wheelhouse or the mudguard. The occurring chimney effect will further increase the entrainment rate, increase the flow and flame spread up along the tyre surface and increase the heat release rate.

Given the high heat release rate and extensive smoke production of tyre fires, fire protection measures should be aimed at preventing the ignition of the tyre as well as reducing the risk of the fire spreading to an adjacent fuel item from the tyre. Given the high critical heat flux of a tyre, the chance of preventing a tyre ignition is considered favourable [3].

\section{Full-Scale Fire Experiments and CFD Simulations}

\subsection{Full-Scale Fire Experiments}

Two full-scale fire experiments on a loader (a Toro 501 DL) and a drilling rig (an Atlas Copco Rocket Boomer 322) took place in an underground mine. One of the experimental objectives was to collect data on the fire behaviour of mining vehicles and several parameters were either measured or later calculated. Measured parameters were for example the mass flow rate in the mine drift, gas concentrations downstream of the fire, temperatures occurring both at the burning vehicle items and further downstream of the burning vehicles. The experimental setup can be seen in Fig. 1. At the measuring station downstream of the mining vehicles, numerous sensors were positioned at different heights to foremost provide data for the heat release rate calculations. A total of six thermocouples, four velocity probes and one gas analysis $\left(\mathrm{O}_{2}, \mathrm{CO}\right.$ and $\left.\mathrm{CO}_{2}\right)$ were found at the measuring station. The initial fires were pool fires and consisted of circular trays filled with diesel which were placed underneath the fuel tank and close to one of the tyres. After ignition the burning diesel would rapidly ignite the adjacent tyre and ensure a continuous fire spread to other fuel components. Further detailed descriptions of the conducted experiments can be found in a report by Hansen and Ingason [26].

The wheelhouse and mudguard of the wheel loader and the mudguard of the drilling rig can be seen in Figs. 2 and 3 respectively. In the case of the wheel loader, the rear tyres were positioned in wheelhouses and the front tyres were equipped with mudguards. All four tyres of the drilling rig were fitted with a mudguard of similar construction. The horizontal distance from the centre of the wheel rim of the drilling rig to the mudguard cover was $0.635 \mathrm{~m}$. The corresponding distance in the loader case was approximately $1 \mathrm{~m}$.

The characteristics of the wheelhouses and mudguards varied considerably. The rear wheelhouses of the loader were built into the vehicle construction, decreasing the exposure to the ventilation flow. The wheelhouses were enclosed by large masses of metal constructions and only 
Fig. 1 The experimental setup at the test site (not to scale) [26]

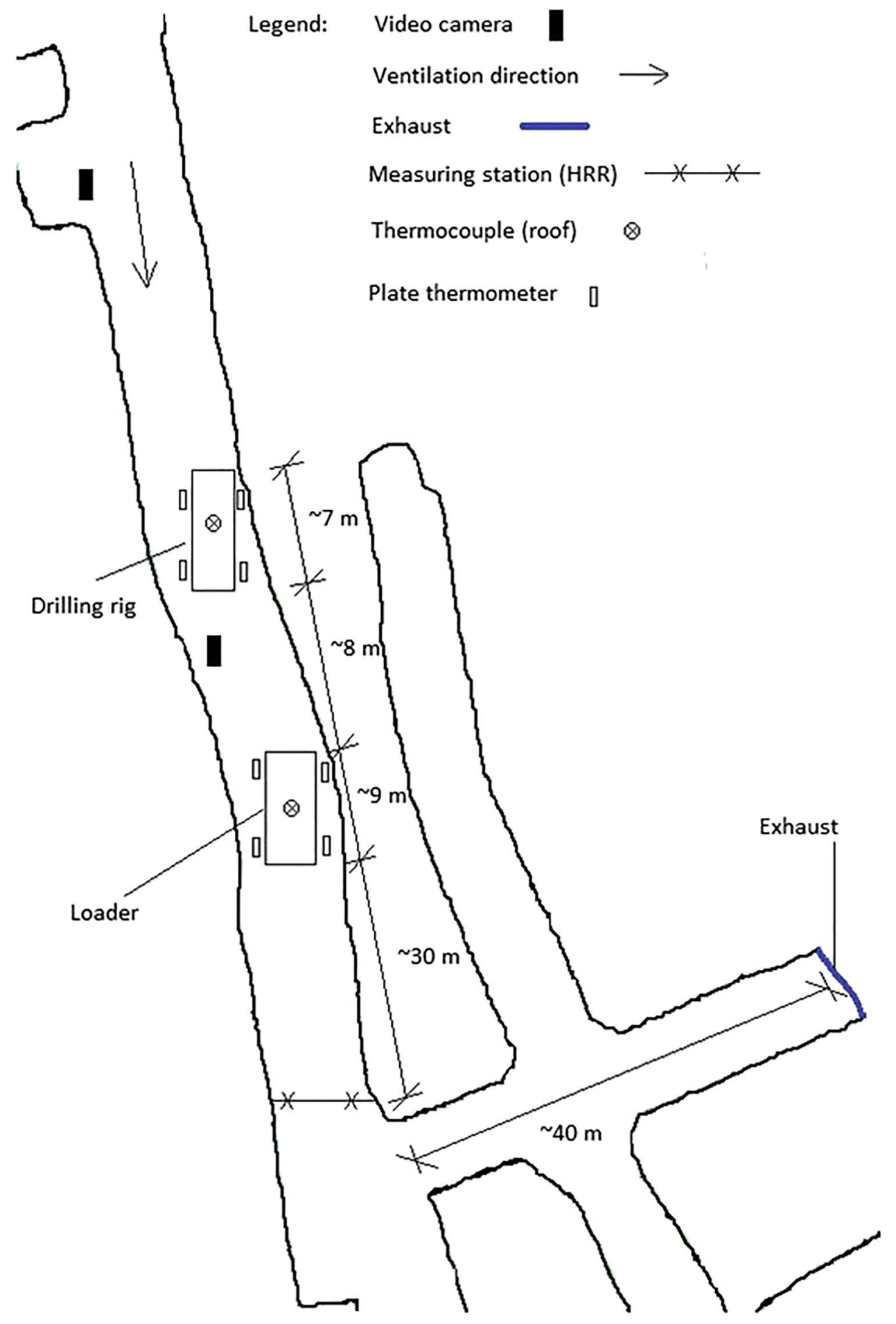

marginally exposed to the ventilation flow underneath the vehicle $(0.355 \mathrm{~m}$ between the ground and the underside of the vehicle). The front mudguards of the loader were set apart from the main body and only partially covering the tyres as seen in Fig. 2. The mudguard of the drilling rig was set apart from the main body of the vehicle, with increased exposure to the ventilation flow. The mudguard consisted of a thinner steel construction with openings towards main body of the vehicle. The distance between the lower level of the mudguard and the ground was equivalent to the loader case.

In the case of the drilling rig experiment, all four tyres were ignited and took part in the fire, whereas, in the case of the wheel loader, only the rear tyres took part in the fire and the front tyres never ignited. 


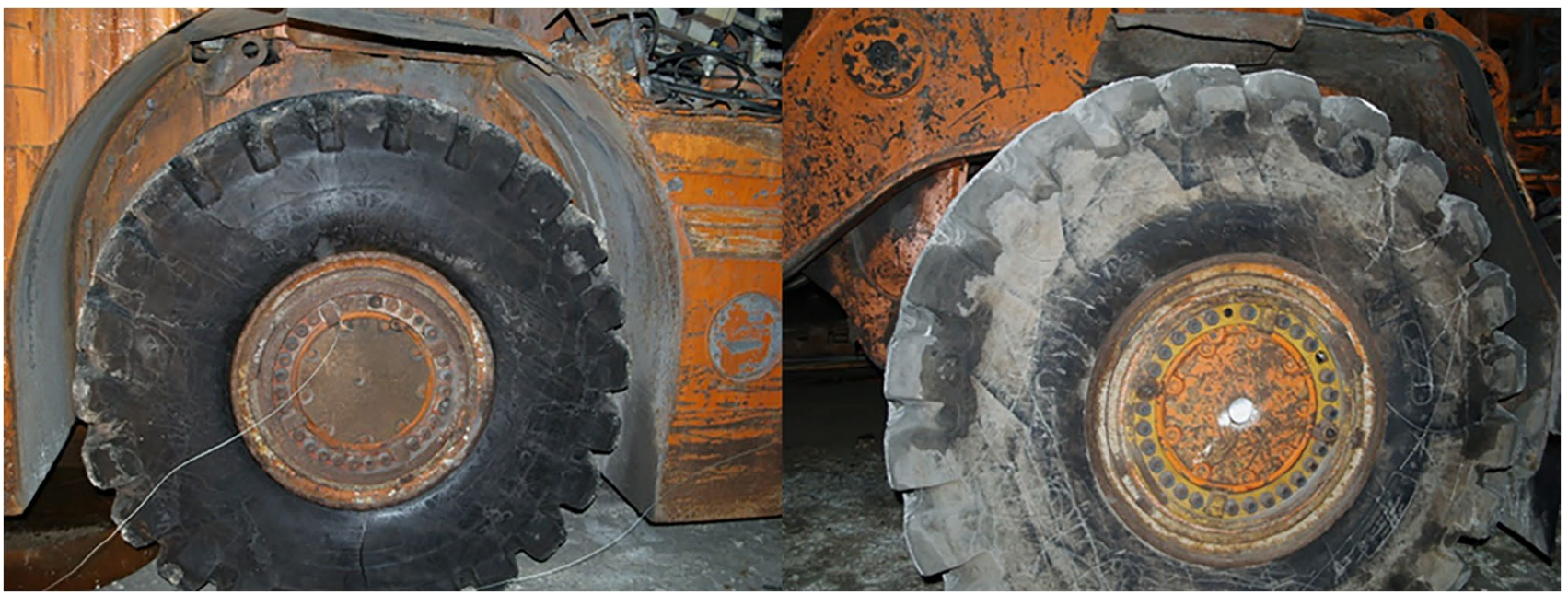

Fig. 2 The wheelhouse of the rear right tyre (seen on the left) and the mudguard of the front left tyre (seen on the right) of the loader

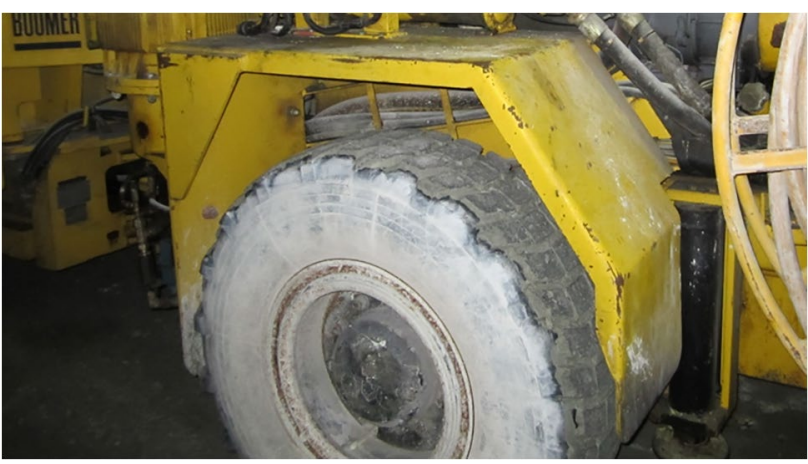

Fig. 3 The left rear tyre and mudguard of the drilling rig

The wheel loader had the following tyre dimensions: $26,5 \times 25$ L5S, which signifies a tyre with a section width of 26.5 inches, a rim diameter of 25 inches and with smooth extra deep tread. The drilling rig had the following tyre dimensions: $13,00 \times 20 \mathrm{PR} 18$, which signifies a tyre with a section width of 13 inches and a rim diameter of 20 inches.

A mobile fan (a Tempest fan model MGV L125) positioned upstream of the fires, provided the longitudinal ventilation flow during the experiments. The fan had a capacity of $217,000 \mathrm{~m}^{3} / \mathrm{h}\left(\sim 60.3 \mathrm{~m}^{3} / \mathrm{s}\right)$. The direction of the ventilation flow vs the setup of the mining vehicle was identical in the two experiments; i.e. the ventilation flow was parallel to the vehicle and facing the rear of the vehicles. During the wheel loader experiment, the average ventilation velocity - measured downstream of the fire position - at the time of ignition was measured at $0.3 \mathrm{~m} / \mathrm{s}$. The average ventilation velocity between ignition and the time of maximum heat release rate was in the interval $0.3-2.2 \mathrm{~m} / \mathrm{s}$. The changes in the ventilation velocity if comparing with the velocity at ignition were caused by the fire effecting the flow field. During the drilling rig experiment, the average ventilation velocity at the time of ignition was measured at $1.3 \mathrm{~m} / \mathrm{s}$. Between ignition and the time of maximum heat release rate, the average ventilation velocity was in the interval $1.1-2.6 \mathrm{~m} / \mathrm{s}$.

The wheel loader was equipped with several different measuring points during the experiment. Each tyre was fitted with a thermocouple, positioned on the wheel rim (see the rear right tyre in Fig. 2). A plate thermometer (providing data for calculating the heat flux) was positioned at each tyre. Each plate thermometer was positioned in line with the rear edge of the tyre, facing the vehicle in the case of the rear tyres and facing the rear of the vehicle in the case of the front tyres.

The drilling rig was fitted with thermocouples on each tyre. The thermocouples were positioned on the upper part of the mudguard, facing the tyre and outwards (see Fig. 4). The inner part of the rear wheel/tyre sections was also equipped with a thermocouple (see Fig. 4). Same as for the wheel loader, plate thermometers were positioned at each tyre. The difference in the thermocouple positioning between the two vehicles was due to practical reasons as it was found to be difficult to attach the thermocouples and ensuring they remain in position at the wheelhouse/ mudguard of the loader.

A video camera was positioned upstream of the fire in each experiment, facing the right and rear section of the vehicles. Video recordings from the experiments provided valuable information on occurring phenomena, changing conditions etc. 
Fig. 4 The position of the thermocouple above one of the tyres (seen on the left) and the position of the thermocouple at the inner part of the wheel/tyre section (seen on the right) drilling rig experiment

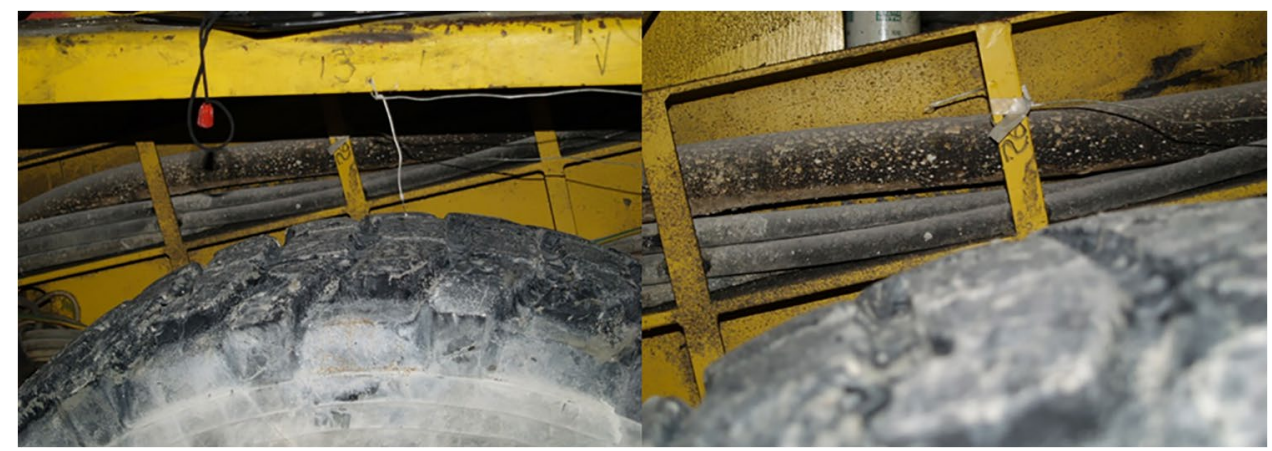

\subsection{CFD Simulations}

The CFD simulations were performed primarily to obtain data for a qualitative analysis, studying the overall flow situations with respect to the temperature and velocity. CFD simulations are a commonly used tool when modelling fire scenarios, predicting heat transfer, ventilation flow etc. CFD simulations are foremost suited for near field simulations - i.e. the area close to the fire - as the simulations will otherwise become very time consuming and computationally very demanding.

A CFD model is used to solve equations governing the fluid flow, where the conservation of mass, conservation of momentum and conservation of energy are the fundamental equations.

A challenge when using CFD models to predict fire phenomena is the turbulence, which generally occurs during fires. The complexity of turbulence will require an impossible resolution to solve the quantities of interest, instead numerical turbulence models are used to approximate quantities. A commonly used turbulence model is the large eddy simulation (LES), where the smaller eddies are approximated by numerical models. Direct numerical simulation (DNS) resolves the entire range of length scales and is therefore much more computationally demanding.

\subsubsection{FDS Parameters}

The Fire Dynamics Simulator (FDS) was selected as the modelling software due to the program's suitability for the low-speed thermally driven flow of a fire and the extensive use for fire applications for several years. The specific version used during the simulations was version 6.7.5 [27].

One of the most central questions when performing fire modelling with a CFD model is the grid size of the mesh applied in the simulations. A grid size which is too large will decrease the accuracy and the confidence in the modelling results and a too small grid size will be computationally demanding with no differences in the output results. McGrattan et al. [27] presented the following resolution of the fire plume flow field, applying a characteristic fire diameter $\left(D^{*}\right)$ :

$D^{*}=\left(\frac{\dot{Q}}{\rho_{a} \cdot c_{p} \cdot T_{a} \cdot \sqrt{g}}\right)^{2 / 5}$

Earlier studies have shown that a mesh grid size smaller than the range $0.075 \cdot D^{*}-0.1 \cdot D^{*}$ will result in output results being grid size independent [28]. Each tyre fire in the full-scale experiments involving a loader and a drilling rig was estimated at a maximum of $1.4 \mathrm{MW}$ in the drilling rig case and 4.1 MW in the loader case [25]. Based on the heat release rates and the characteristic fire diameter range, a mesh grid size of $0.04 \mathrm{~m}$ was selected for both the drilling rig and the loader case, applying a uniform mesh grid size for the entire domain. The LES mode was chosen for the simulations as grid size-independent results would be ensured using the LES mode.

The dimensions of the modelled domain were $10 \mathrm{~m}$ in length (in the direction of the longitudinal ventilation flow and set to the $\mathrm{x}$-direction), $4 \mathrm{~m}$ in width (y-direction) and $5 \mathrm{~m}$ in height (z-direction). Taking advantage of the symmetry, the entire drilling rig and loader were not included in the simulations as the focus was on the fire behaviour along the side of the vehicle, with a burning tyre and the longitudinal ventilation flow streaming along the side. Approximately half the width of the vehicle was included in the simulations, explaining the somewhat reduced mine drift width of the modelled domain. The schematics of the modelled domain and vehicles can be seen in Figs. 5, 6,7 and 8. For a detailed description of the two mining vehicles, see a report by Hansen and Ingason [26]. Any details in the domain - cab, tyre etc. - were made up of rectilinear volumes. Thus, the circular geometry of the tyres was approximated by numerous rectilinear volumes to achieve rounded surfaces.

The burning tyre was the rear tyre in all simulations and where the front tyre was downstream of the fire. The fuel in the simulations consisted of burning tyre surfaces. When modelling the heat release rate of the tyre fires, the heat 
Fig. 5 The modelled domain of the drilling rig simulations, $\mathrm{xz}-$ plane. $\mathrm{Cab}$ and mudguards seen in red, and rear tyre (fire object) seen in yellow
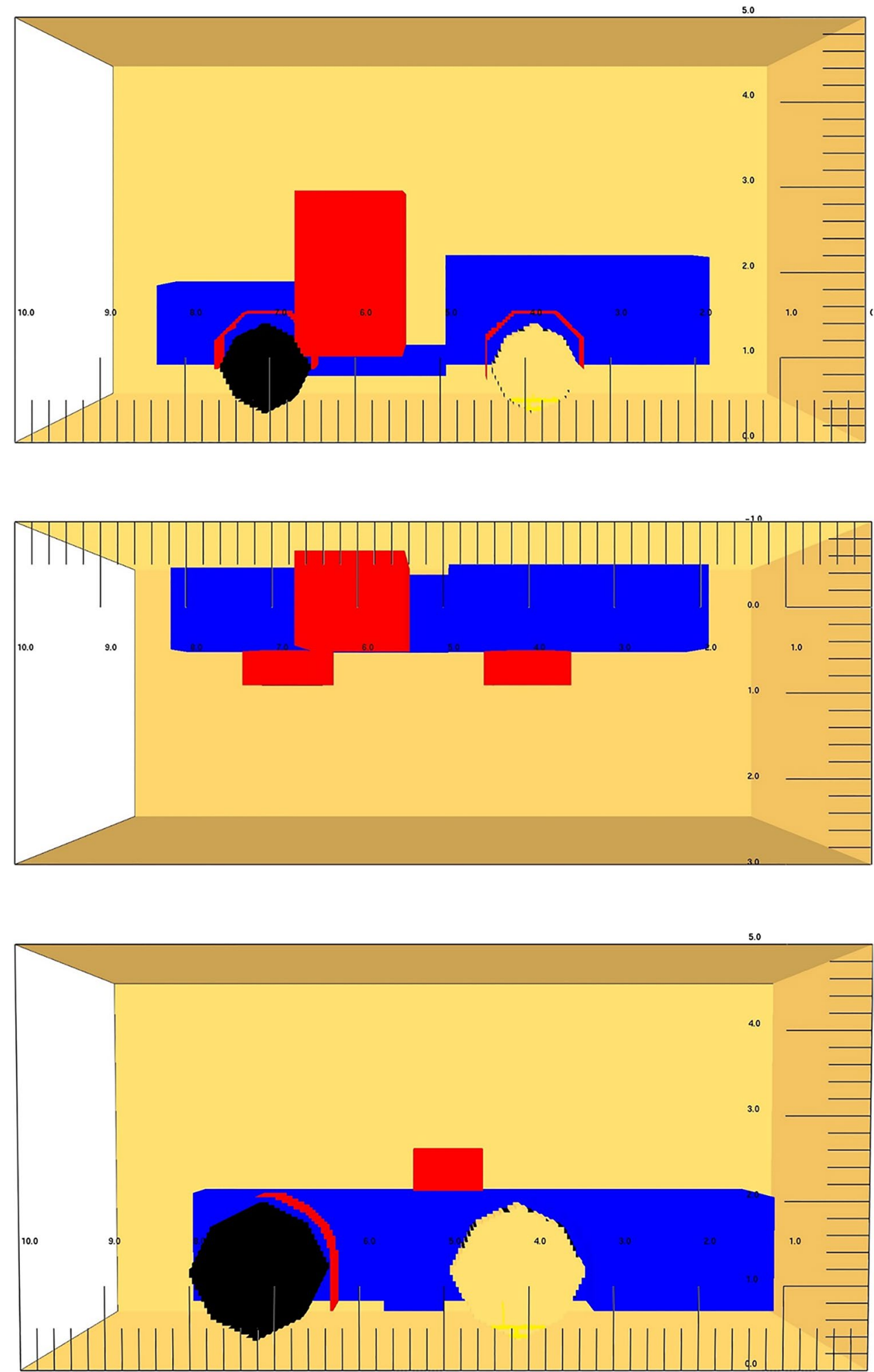

Fig. 7 The modelled domain of the loader simulations, $x z-$ plane. $\mathrm{Cab}$ and mudguard seen in red, and rear tyre (fire object) seen in yellow
Fig. 6 The modelled domain of the drilling rig simulations, xy-plane. Cab and mudguards seen in red 
Fig. 8 The modelled domain of the loader simulations, $x y-$ plane. Cab and mudguard seen in red

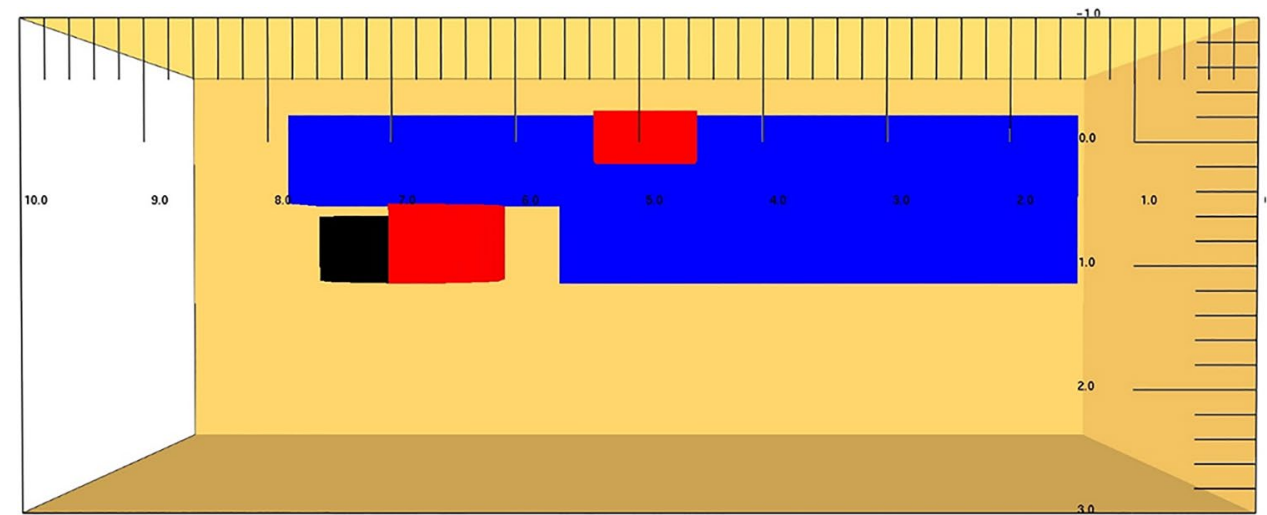

release rate per unit surface area was ramped in accordance to earlier developed exponential functions based on the full-scale experiments [25], attaining the maximum heat release rate after $240 \mathrm{~s}$ in the loader case and $540 \mathrm{~s}$ in the drilling rig case, and the simulations were continued for another $50 \mathrm{~s}$ with a constant heat release rate and thus totalling $290 \mathrm{~s}$ and $590 \mathrm{~s}$ in time length. Only the heat release rates of the rear tyre were included in the simulations to isolatedly and specifically study the effects of the tyre fires.

The radiative heat transfer was set in default operation solving the radiation transport equation for a grey gas - and the surrounding surfaces of the modelled mine drift consisted of Dolomite - as in the full-scale fire experiments. The ambient temperature was set to $10^{\circ} \mathrm{C}$ in all simulations, equivalent to the temperature in the full-scale experiments.

The fan in each simulation provided a uniform volumetric flow rate. The inlet (at the position of the fan) was set to velocity boundary and the exhaust was set to open at atmospheric pressure. Three different ventilation flow velocities were applied in the simulations: $0.5 \mathrm{~m} / \mathrm{s}, 1.0 \mathrm{~m} / \mathrm{s}$ and $2.0 \mathrm{~m} / \mathrm{s}$. The ventilation flow velocity was ramped linearly — attaining the desired flow velocity after $100 \mathrm{~s}$ - to reduce the risk of numerical instability. The focus of the simulations was the result at the end of the simulations when the maximum flow velocity and heat release rate had prevailed for some time. The heat release rate curves were not varied with increasing flow velocity to isolatedly study the effects of the flow velocity. The influence of a varying heat release rate was accounted for when comparing the drilling rig case with the loader case for the same flow velocity.

During the simulations, planar slices of data (temperature and velocity) as well as the three-dimensional contour of the $300{ }^{\circ} \mathrm{C}$ temperature isosurface were recorded. The planar slices were positioned directly above the wheelhouse/mudguard (xy-plane) as well as directly adjacent to the wheelhouse/mudguard (xz-plane). Measuring points (temperature) were also added on the outside of the right, front tyre and waist of the two vehicles, positioned in accordance with thermocouples in the experiments. The temperature data was used in conjunction with the planar slice data.

Simulations were performed to validate the output results of the CFD model against the results from the full-scale experiments. In the simulations, the domain also comprised the measuring station, where the average gas temperature was measured with thermocouples $0.8,2,3.2$ and $4.4 \mathrm{~m}$ down from the ceiling. The resulting average gas temperatures for the initial $10 \mathrm{~min}$ (included the initial phase with high fire growth rate) can be seen in Fig. 9. The predicted temperatures of the drilling rig as well as the loader fitted well with the experimental temperatures.

\section{Results and Discussion}

\subsection{Full-Scale Experiments}

\subsubsection{General Flame Behaviour}

When studying the video footage from the drilling rig experiment (the video camera was positioned upstream of the drilling rig, facing the right and rear section of the vehicle), the inflow of air and plume flow at the right, rear tyre could be easily discerned. Figure 10 displays an inflow of air at the lower level, where few flames are seen along the tyre surface facing the ventilation flow (except for flames seen in the tyre threads). The flow of air is thus pushing the flames along the tyre surface not protected by the mudguard construction and any flames found along the surface are generally short in length due to the well-ventilated conditions, the exception being the tyre threads where a fuel-rich environment can be found in the voids, causing an increase in the flame length. The flames along the side of the tyre are also shorter in length (approximately 0.1 to $0.2 \mathrm{~m}$ in length) due to the air masses flowing along the side of the vehicle. The wheel rim acted as an inert centre, resulting in a "ring of fire" on the tyre side. On the leeside of the tyre, the flame length was much longer, forming a tilted flame volume. The 
Fig. 9 The average gas temperature at the measuring station

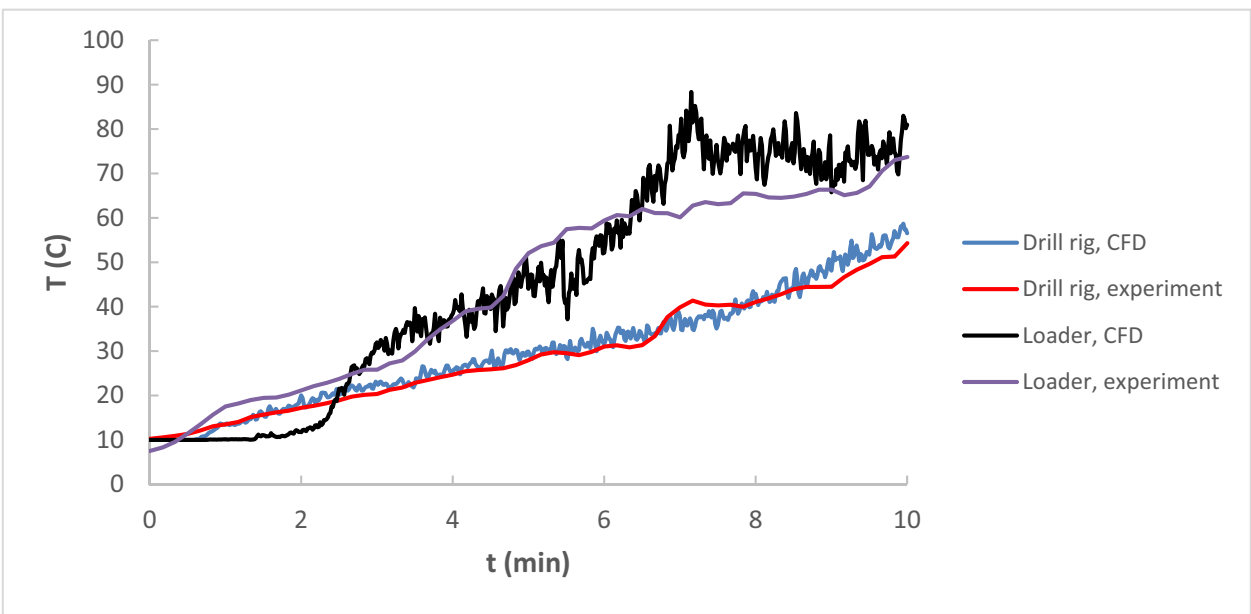

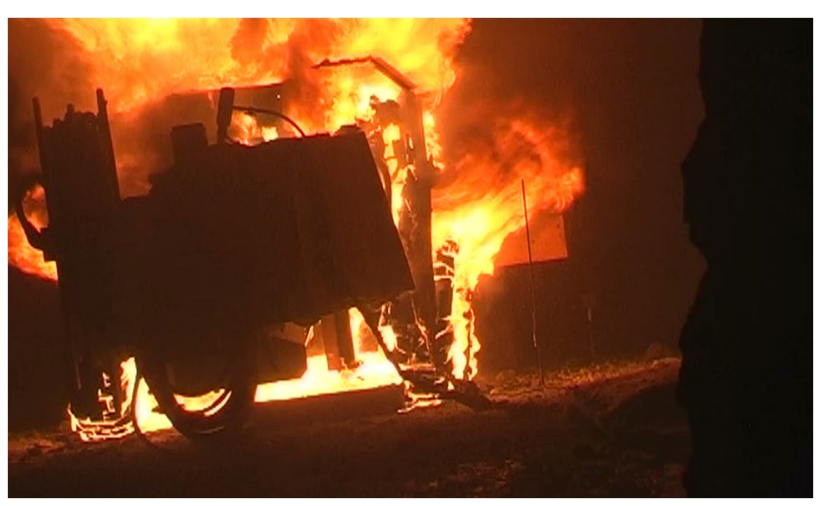

Fig. 10 The drilling rig fire, facing the right and rear section of the vehicle

fire plume ascends towards the upper part of the mudguard, forming a fire gas layer underneath the construction. The fire plume flows out of the construction, slightly twisted into the longitudinal ventilation flow direction and with a considerable flame length. The environment in the upper part of the mudguard can be categorized as fuel rich, due to the mudguard construction enhancing the thermal feedback back to the fuel surface and increasing the pyrolysis and the blockage of the ventilation flow, reducing the entrainment rate. A phenomenon working in the other direction is the Venturi effect, which will cause an increase in the mixing of the flowing air and the emitted fire gases.

\subsubsection{Flame Tilt Angle}

Figure 11 displays the left, rear wheelhouse of the loader after the full-scale fire experiment. The light colour seen on the left side of the wheelhouse indicates areas where the temperature has been very high and has burnt off the soot. The angle will give an indication of the flame tilt angle and was estimated at $72^{\circ}$ (i.e. the angle between the horizontal

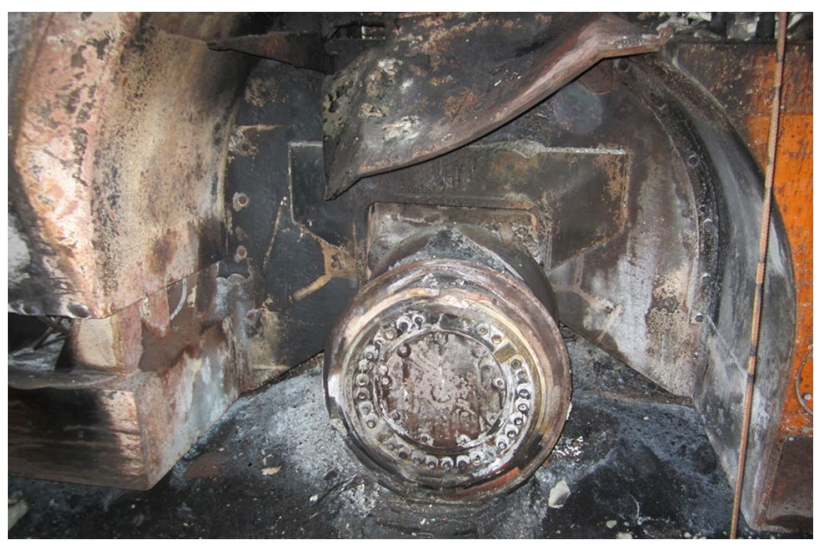

Fig. 11 The left, rear wheelhouse of the loader after the full-scale fire experiment. Photo: Andreas Fransson

and the plume axis). The angle was estimated using technical drawings of the vehicle and photos taken after the fire. The estimated flame tilt angle was compared with the flame tilt angle results applying either Eqs. (1-7) or Eqs. (8-9). The applied heat release rate in the calculations was the maximum heat release rate, assuming the burn marks would mainly occur during the period with the highest intensity and temperatures. The maximum heat release rate of the loader tyre was calculated using a maximum heat release rate per exposed surface area of $0.20 \mathrm{MW} / \mathrm{m}^{2}$ [29] and a total outer surface of $10.2 \mathrm{~m}^{2}$. The heat release rate per exposed surface area will vary depending on the incident heat flux and the fuel surface underneath the mudguard will be exposed to higher heat fluxes, resulting in a higher heat release rate. The maximum heat release rate per exposed surface area will account for the increase, providing a value applicable for the period containing the peak heat release rate. To account for the increased heat release rate due to the porosity characteristics of the tyre threads, the maximum heat release rate was increased with 
a factor 2 [25]. The mobile fan providing the longitudinal ventilation flow during the maximum heat release rate of the tyre fire, was operated at the same rotational speed and from the same position as during the entire drilling rig experiment. As the mobile fan was operated at different rotational speeds and from different positions during the early stages of the loader experiment, the average flow velocity from the drilling rig experiment was used instead. The average, measured flow velocity prior to ignition at the lowest bi-directional probe was applied in the calculations, being closest to the mid-height of the loader tyre. The mid-height of the tyre is assumed to be above the boundary layer. The volumetric flow rate and the flow velocity were assumed to be constant in the calculations. Applying Eqs. (1-7) results in a flame tilt angle of $79^{\circ}$ and applying Eqs. (8-9) a flame tilt angle of $77^{\circ}$. Applying the principle of mass continuity and accounting for the Venturi effect (adjusting the ventilation flow velocity by using the blockage ratio of the drilling rig) resulted in a flame tilt angle of $65^{\circ}$ using Eqs. (1-7) and an almost unchanged tilt angle of $76^{\circ}$ using Eqs. (8-9). An unchanged flame tilt angle when accounting for the accelerated flow due to the Venturi effect is highly unlikely. If comparing the estimated flame tilt angle from the experiment and the calculated tilt angle of Eqs. (1-7) - which are based on free burning fire sources - and accounting for the Venturi effect, the wheelhouse will have an effect on the flame tilt angle. This specific wheelhouse construction will increase the angle by approximately $10 \%$. A higher flame tilt angle is generally desired to decrease the risk of fire spread in the direction of the ventilation flow. A higher flame tilt angle will decrease the risk of flame impingement and decrease the incident heat flux on fuel items downstream. Nevertheless, with a higher flame tilt angle, the surroundings above the wheelhouse or mudguard will have to be analysed with respect to combustible fuel items, mitigating the risk of fire spread in the vertical direction.

Even though the above experimental observation and calculations contain several different assumptions and simplifications, the resulting approximative angles will give an indication on the impact of the wheelhouse. The nearby metal surfaces of the wheelhouse will alter the flame behaviour - effecting the risk of fire spread - and a longitudinal ventilation flow will add further to the complexity.

\subsubsection{Flame Temperatures and Flame Lengths}

The flame temperature will vary depending on factors such as the type of fuel involved, soot formation during the fire, size of fire and ventilation conditions. With increasing soot formation or decreasing fire size, the flame temperature will decrease. With decreasing supply of oxygen - resulting in a fuel-rich environment - the energy released will decrease and unburned fuel components will absorb energy from the combustion, resulting in a decreased flame temperature.

Baum and McCaffrey [30] divided the fire plume into the following three zones: continuous flame zone, intermittent zone and plume zone. The continuous flame zone is fully engulfed in flames, where the centreline temperature is constant. In the intermittent zone - found above the continuous flame zone - flames are intermittently present, whereas in the plume zone no combustion takes place, and no flames are present. The flame temperature in the continuous flame zone will be of high interest when analysing the fire spread to adjacent fuel items as the visible flame is continuously present in the zone.

Each drilling rig tyre was equipped with a thermocouple, positioned in between the upper part of the mudguard and the tyre (see Fig. 4 for the position). As seen in Fig. 10, the thermocouples would be well within the continuous flame
Fig. 12 The temperature measurements at the right, rear tyre (Tc11), left, rear tyre (Tc13) and the left, front tyre (Tc14) drilling rig fire

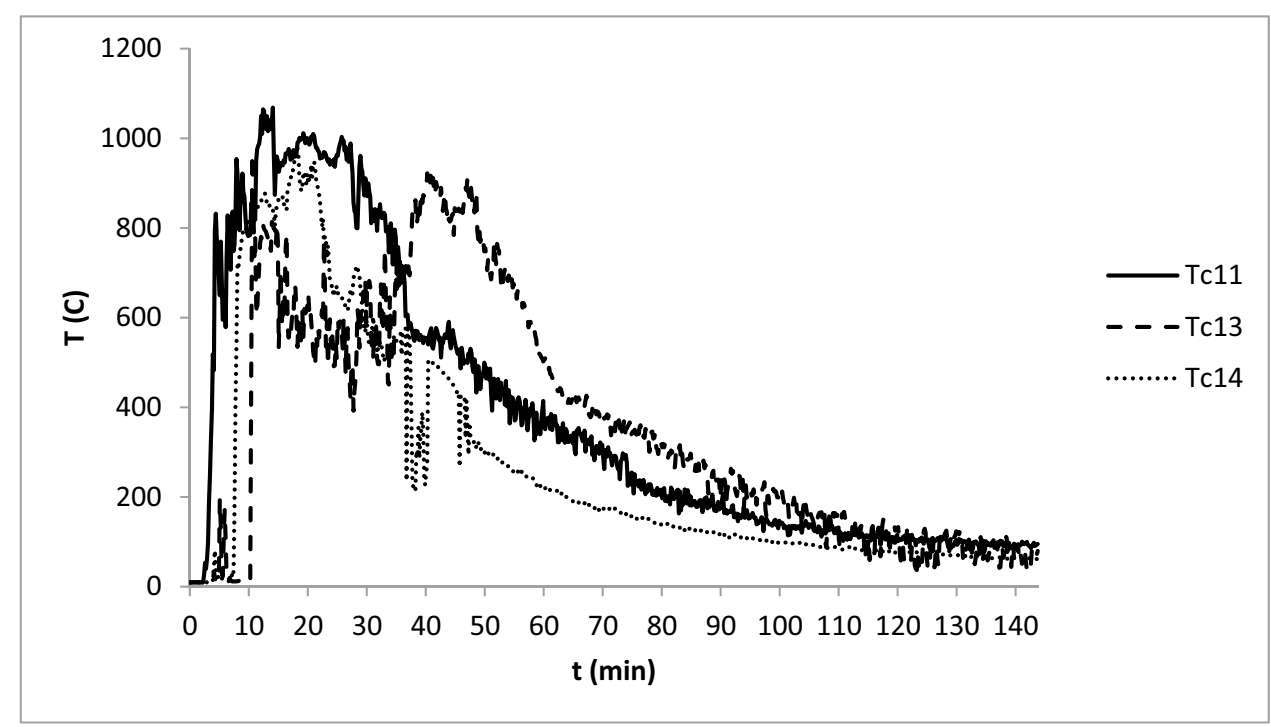


zone during parts of the fire. Figure 12 displays the temperature recordings from the thermocouples at the right, rear tyre (Tc11), left, rear tyre (Tc13) and the left, front tyre (Tc14). The thermocouple at the right, forward tyre (Tc12) stopped functioning after approximately $12 \mathrm{~min}$ from the time of ignition. All three temperature curves contain a plateau phase where the temperature stays constant and where the thermocouples were fully engulfed in flames. Calculating the average temperature of all three plateau phases resulted in a flame temperature of $921^{\circ} \mathrm{C}$.

Figure 2 displays the position of the thermocouple on the loader wheel rim. Only the rear tyres took place in the fire during the loader experiment and when calculating the average temperature of the plateau phase of the left, rear tyre a flame temperature of $863{ }^{\circ} \mathrm{C}$ was received (see Fig. 13 for the temperature recordings). The lower flame temperature of the loader tyre was most likely due to an increased soot formation, which in turn depended on a different composition of the tyre material.

When comparing with flame temperatures of other materials or substances, the calculated flame temperature of the drilling rig tyre is found in the upper region whereas the loader tyre temperature is found within the typical range of $800-900{ }^{\circ} \mathrm{C}[31-33]$ for the continuous flame zone for various types of fuels. A higher flame temperature will increase the risk of ignition of adjacent fuel items and decrease the time to ignition, contributing to a fire with higher intensity and larger impact on the surroundings.

Studying the video recordings from the drilling rig experiment, the flame length of the rear, right tyre was estimated from the recordings. Flame lengths during sudden eruptions were neglected, focusing instead on the flame length during steady-state periods. Measuring from the top of the tyre and adjusting for the tilt angle, the flame length was estimated at approximately $0.9 \mathrm{~m}$. When measuring the flame length, the flame length was defined as the extent of the continuous flame zone. When adjusting for the tilt angle, the Venturi effect was accounted for and similar degree of impact from the mudguard construction as in the loader case was assumed. Calculating the flame length using Eqs. (10-11), a flame length of approximately $0.3 \mathrm{~m}$ resulted. An unrealistically high flame length resulted when using Eq. (12). Equations (10-11) have been validated against full-scale tunnel fires and the question is why the observed flame length differs so much from the calculated flame length? The pool fire adjacent to the tyre would have contributed to a longer flame length, explaining some of the discrepancy. Still, the construction of the mudguard would have largely contributed to the extended flame length by creating a fuel-rich environment and reducing the entrainment rate. The chimney effect and the Venturi effect would have worked in the other direction, increasing the entrainment rate but the mudguard construction would have had a larger impact on the flame length. A longer flame length would increase the risk of ignition of adjacent fuel items, as the risk of flame impingement would increase and the incident heat flux on fuel surfaces would increase due to shorter distance to flames. Longer flame lengths due to mudguard construction would therefore have to be considered when for example positioning combustible items in the vicinity of the mudguard.

Even though a lower heat release rate and a different construction enclosing the drilling rig tyre would result in a different flame tilt angle compared with the loader case, the difference between the measured and the calculated flame length is so significant that the flame length extending characteristics of the mudguard is evident.

Estimation of the corresponding flame length of the loader was not possible as the camera was aimed at the lower section and the video recordings did not display the full extent of the flame length.
Fig. 13 The temperature measurements at the left, rear tyre (Tc13) - loader fire

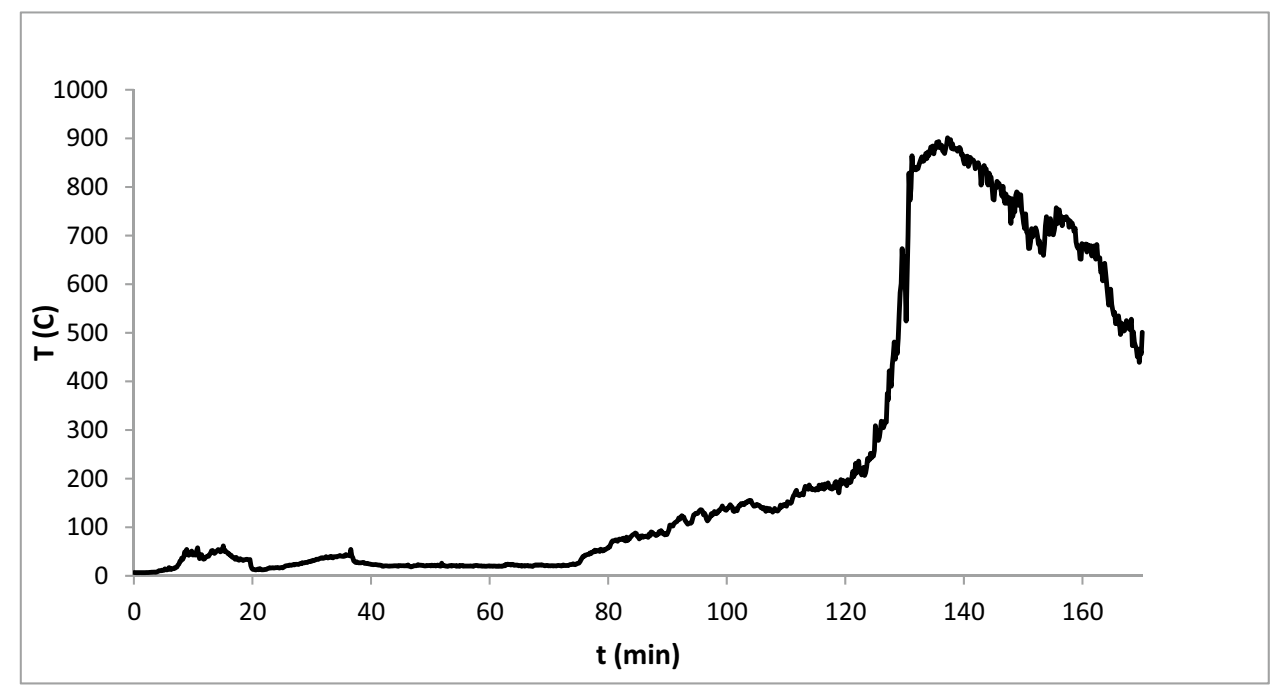




\subsubsection{Impact on Nearby Fuel Items}

A plate thermometer (PTC21) was positioned at the left, rear drilling rig tyre, providing data for the calculation of the heat flux from the tyre fire. The plate thermometer was in line with the rear edge of the tyre, facing the vehicle at a distance of $0.5 \mathrm{~m}$. During the drilling rig experiment, a maximum incident heat flux of $28.8 \mathrm{~kW} / \mathrm{m}^{2}$ was recorded at the tyre. The recorded value comes very close to the corresponding value of the left, rear loader tyre: $29.4 \mathrm{~kW} / \mathrm{m}^{2}$. Applying the following expression for calculating the radiant heat flux at a distant point:

$\dot{q}_{r}^{\prime \prime}=\phi \cdot E$

where $\dot{q}_{r}^{\prime \prime}$ is the radiant heat flux $\left(\mathrm{kW} / \mathrm{m}^{2}\right), \phi$ is the dimensionless view factor and $E$ is the net emissive power of the flame $\left(\mathrm{kW} / \mathrm{m}^{2}\right)$, the radiant heat flux was calculated at different distances from the burning tyre. When calculating the view factor between the tyre flames and the plate thermometer, the view factor was divided into the following two cases:

- A differential planar element to a finite parallel rectangle [34], where the finite parallel rectangle is represented by the flames from mid-height of the tyre to the top of the continuous flame zone (applying the earlier estimated maximum flame length).

- A planar element to a semi-circular disk in a parallel plane [34], where the semi-circular disk is represented by the flames from the ground to the mid-height of the tyre.

To simplify the calculations, the wheel rim is assumed to be covered by flames and the flame tilt angle is not considered. As the view factor expressions given by Hottel [34] represent the view factor from a differential area to a finite area, the reciprocity relation for a view factor between a differential and finite area was applied [35]. The resulting incident heat flux as a function of the distance from the burning tyre can be found in Fig. 14. Table 1 lists the critical heat fluxes of materials typically found in underground mines and on mining vehicles. The critical heat flux is one of the typically used ignition criterion, where ignition occurs when the incident heat flux exceeds the critical heat flux. As noted from Table 1 and Fig. 14, a tyre fire is less likely to ignite a tyre on an adjacent vehicle but more likely to ignite hoses or cables on the vehicle. Table 1 and Fig. 14 could for example be used when analysing safety distances to decrease the risk of ignition from a tyre fire. Be aware that the critical heat flux values found in Table 1 are for piloted ignition - where the ignition source consists of a spark igniter - and the critical heat flux for autoignition of

Table 1 Critical heat fluxes and ignition temperatures of materials typically found in underground mines and on mining vehicles

\begin{tabular}{lll}
\hline Material & $\begin{array}{l}\text { Critical heat } \\
\text { flux }(\mathrm{kW} / \\
\left.\mathrm{m}^{2}\right)\end{array}$ & $\begin{array}{l}\text { Ignition } \\
\text { temperature } \\
\left({ }^{\circ} \mathrm{C}\right)\end{array}$ \\
\hline $\begin{array}{l}\text { Tyre } \\
\text { Hydraulic hose (Nitrile-Butadiene } \\
\quad \text { Rubber) }\end{array}$ & $\begin{array}{l}17.1[25] \\
\begin{array}{l}\text { Electrical cable (flame retardant polyu- } \\
\text { rethane) }\end{array}\end{array}$ & $\begin{array}{l}297[37] \\
335[38]\end{array}$ \\
$\begin{array}{l}\text { Wood (Monterey pine, 11\% moisture } \\
\text { content) }\end{array}$ & $10.8[36]$ & $340[36[36]$ \\
$\begin{array}{l}\text { Conveyor belt (Styrene Butadiene } \\
\text { Rubber) }\end{array}$ & $10-15[37]$ & $360[36]$ \\
\hline
\end{tabular}

Fig. 14 The calculated heat flux from the drilling rig tyre at different distances

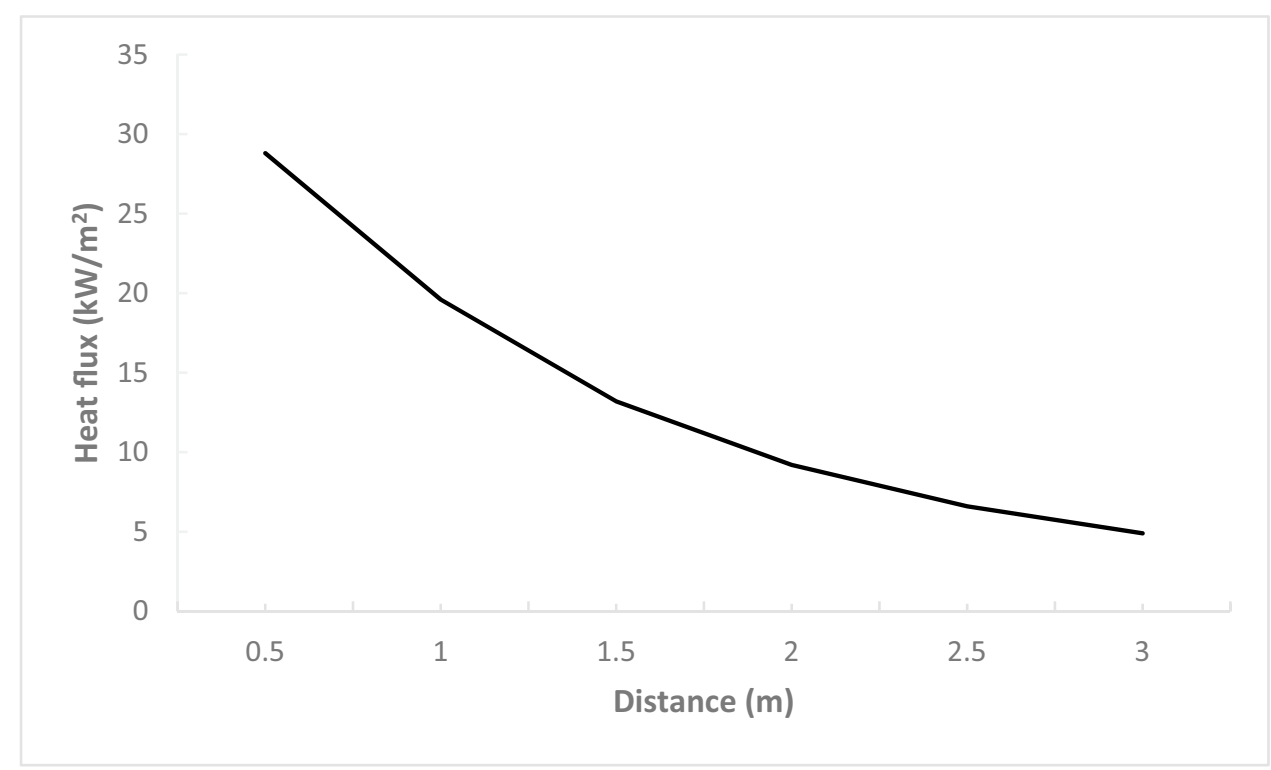


a material is obviously higher, for example $20 \mathrm{~kW} / \mathrm{m}^{2}$ for wood [36]. Still, a feasible fire scenario could include the autoignition of a material with lower critical heat flux, which in turn could act as a pilot ignition source of a material with higher critical heat flux.

Plate thermometers were also positioned at the front tyres, with PTC20 positioned in line with the rear edge of the front, right tyre and PTC22 in line with the rear edge of the front, left tyre. In both cases did the plate thermometer face the rear section of the vehicle and at $0.5 \mathrm{~m}$ from the tyre. Figure 15 displays the incident heat flux at PTC20 (PTC22 ceased to function after $10 \mathrm{~min}$ ) in the drilling rig experiment and Fig. 16 displays the incident heat flux at PTC20 and PTC22 in the loader experiment (PTC20 ceased to function after $40 \mathrm{~min}$ ). As seen, the incident heat flux at the right, front tyre was significantly higher during the drilling rig experiment compared with the loader experiment. A question here is why the drilling rig experiment resulted in so much higher heat flux values? Several factors point in the other direction: the shorter distance between the front and rear tyres of the loader and the higher heat release rates of the loader tyre fire and the adjacent pool fire. As the blockage ratio of the two vehicles was very similar and that the mobile fan operated at the same rotational speed and from the same position throughout most of the experiments, the influence of the longitudinal ventilation was expected to be similar in the two experiments. A factor possibly pointing towards higher heat fluxes in the case of the drilling rig is the occurrence of cable/hose fires at the mid-section. Cables and hoses found in the lower parts of the mid-section exposed to both the rear and front tyres - would easily have been ignited by the rear tyre and then in turn exposed the front tyre for higher heat fluxes due to a very short distance. The same fuel configuration could not be found in the loader case. This observation is further strengthened by midsection temperature measurements, where the temperature was approximately $800{ }^{\circ} \mathrm{C}$ in the drilling rig case but only approximately $100^{\circ} \mathrm{C}$ in the loader case. Yet another factor would be the higher flame temperature from the burning drilling rig tyre.

The inner part of the rear wheel/tyre section of the drilling rig was equipped with thermocouples. The thermocouples
Fig. 15 The calculated incident heat flux at PTC20 in the drilling rig experiment
Fig. 16 The calculated incident heat flux at PTC20 and PTC22 in the loader experiment
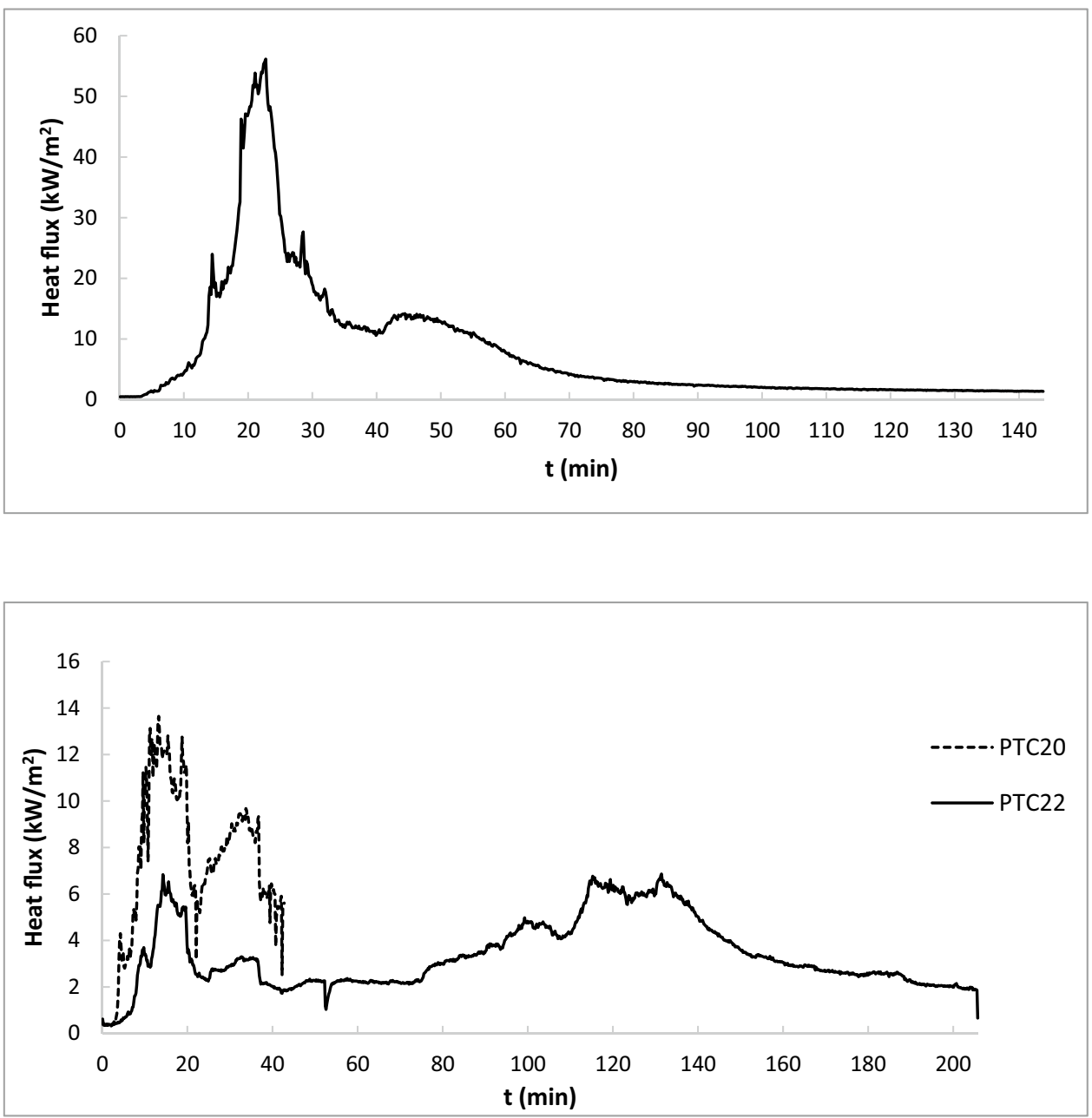
were positioned at the openings towards the main body of the vehicle (see Fig. 4 for the position). Both thermocouples measured temperatures exceeding $800{ }^{\circ} \mathrm{C} 10 \mathrm{~min}$ after ignition and for $30 \mathrm{~min}$. As seen from the ignition temperatures found in Table 1 and given the high temperatures in the enclosure of the mudguard, any combustible material exposed to the hot fire gas flow through for example openings will most likely ignite at an early stage. Any shielding measures - for example, a metal plate covering the inner part of the wheel/tyre section - would prevent or at least delay the ignition of any hoses or cables in the section.

\subsection{CFD Simulations}

\subsubsection{Flame Tilt Angle}

The variations of the flame tilt angle were studied using the isosurface and planar slice data from the simulations as the angle was easiest to discern if using this data. Studying the flame tilt angle at the end of the simulations, it was found that the flame tilt angle for a longitudinal ventilation velocity of $0.5 \mathrm{~m} / \mathrm{s}$ was similar for the loader as well as the drilling rig and the flame tilt angle decreased for the 1.0 and $2.0 \mathrm{~m} / \mathrm{s}$ cases but to a larger degree in the loader case. The planar slices (temperature) at the end of the simulations directly adjacent to the wheelhouse/mudguard (xz-plane) can be seen in Fig. 17. If only accounting for the heat release rate of the two tyre fires, the flame tilt angle should have been higher for the loader case compared with the drilling rig case due to a stronger buoyancy force caused by the higher heat release rate.

When studying the flow velocities at the end of the simulations in the direction of the longitudinal ventilation

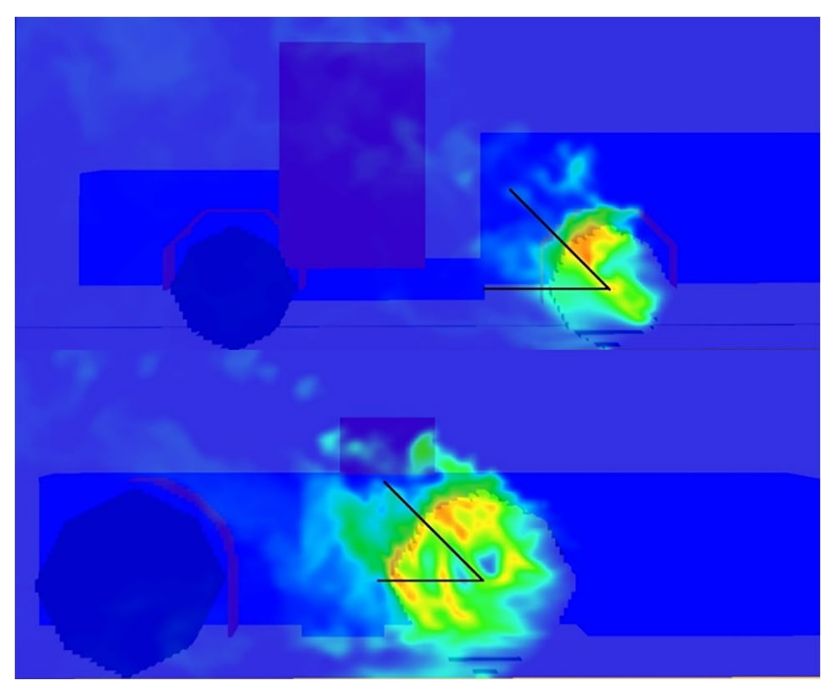

Fig. 17 The xz-plane temperature distribution of the drilling rig (top) and the loader (bottom). A $45^{\circ}$ angle has been inserted to facilitate comparison. Highest temperatures are shown in red and yellow flow for the $2.0 \mathrm{~m} / \mathrm{s}$ simulations, it was found that the flow velocity stayed constant along the outer side of the burning tyre in the drilling rig case. The flow velocity in the loader case initially increased after passing the upstream part of the wheelhouse and decreased when approaching the downstream part of the wheelhouse. The increased flow velocity would contribute to the lower flame tilt angle in the loader case. The lower and decreasing flow velocities are explained by the fire gases flowing out of the wheelhouse/ mudguard, encountering, and retarding the longitudinal ventilation flow (the retardation is mostly seen in the upper parts where the tyre is enclosed by the wheelhouse). Besides the heat release rate, longitudinal flow velocity and the wheelhouse/mudguard construction, the geometry of the tyre will also influence the flame tilt angle. A larger tyre width will increase the amount of pyrolysis products flowing out of the wheelhouse, decreasing the flow velocity, whereas a larger tyre diameter would decrease the influence of the outflowing pyrolysis products.

\subsubsection{Temperature Distribution}

When studying the temperature distribution (planar slice and thermocouples) in parallel to the ventilation flow, it was found that fire gases with higher temperatures could be seen in the lower parts downstream of the fire to a larger degree in the loader simulations compared to the drilling rig. This is in line with the earlier measured flame tilt angle which was lower in the loader simulations. This could partially be explained by the higher heat release rate and smoke production in the loader case, where the wheelhouse may not ventilate the flames and fire gases as efficiently as in the drilling rig case with lower heat release rate. Some fire gases and flames may thus escape at the lower level towards the front tyre and mudguard as well as along the underside of the vehicle. With increasing tyre dimensions and thus also heat release rate, the risk of hot fire gases and flames escaping at the lower level should be considered. Besides ensuring that combustible items at the lower level are shielded, the flow of flames and fire gases may also be blocked. Even though the flow may not be entirely blocked, any obstruction in the direction of the flow will increase the mixture with the air which in turn will decrease the temperature of the fire gases and decrease the risk of ignition.

When studying the temperature distribution from above, it was found that fire gases with higher temperatures veered in towards the vehicle body in the drilling rig simulations, whereas in the loader simulations the fire gases mostly followed the ventilation flow and swept past the mudguard and the front tyre on the outside. Figure 18 displays the right-hand side of the loader after the fire experiment, as can be seen mostly the outer part of the mudguard was affected by the flow of fire gases (distinguished by 


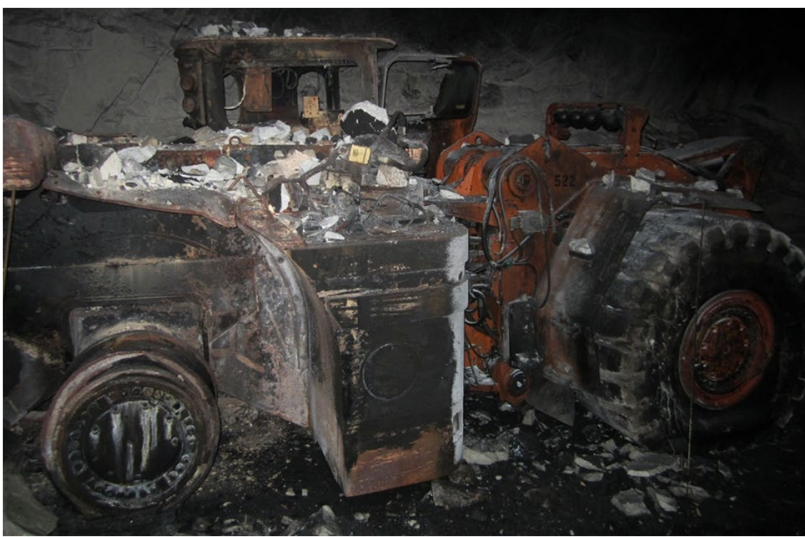

Fig. 18 The right-hand side of the loader with the front mudguard partially affected by the fire. Photo: Andreas Fransson [26]

the higher degree of soot deposit along the outer edge). Besides the higher heat release rate, the construction of the loader contributed to this flow behaviour, where the short distance to the front mudguard/tyre and the separation of flow directly downstream of the protruding construction led to the flow of flames and fire gases being largely steered past the front mudguard/tyre. In the case of the drilling rig, the longer distance to the front mudguard/tyre and the abrupt end of the rear mudguard would have led to the flow of fire gases being directed towards the body of the vehicle after passing the area with flow separation. The distance between the front and rear tyres would thus influence the risk of fire spread through two mechanisms - working in different directions. An increasing distance between the tyres will decrease the radiative heat transfer from the flames and therefore decrease the risk of ignition, but at a longer distance the impact of flow separation will decrease and therefore expose a larger portion of the tyre downstream to the flow of hotter fire gases and flames and thus increasing the risk of ignition. Figure 19 displays the distribution of the $300{ }^{\circ} \mathrm{C}$ isosurface in the xy-plane for the $2.0 \mathrm{~m} / \mathrm{s}$ flow velocity cases.

Despite the shorter distance between the rear and front tyres and the flowing fire gases at the lower level in the loader case, the front tyres of the loader were never ignited in the fire experiment. This could be attributed to the following four factors: the high critical heat flux of the tyre, the mudguard being able to mitigate the impact from the flowing fire gases, the flow of hot fire gases sweeping mostly past the mudguard and on the outside of the tyre, and the absence of cables and hoses directly downstream of the wheelhouse and along the underside of the vehicle. In the case of the drilling rig, the two first factors were fulfilled but not the last two. Cables and hoses along the underside of the drilling rig thus functioned as a bridge in the fire spread between the rear and front tyres.

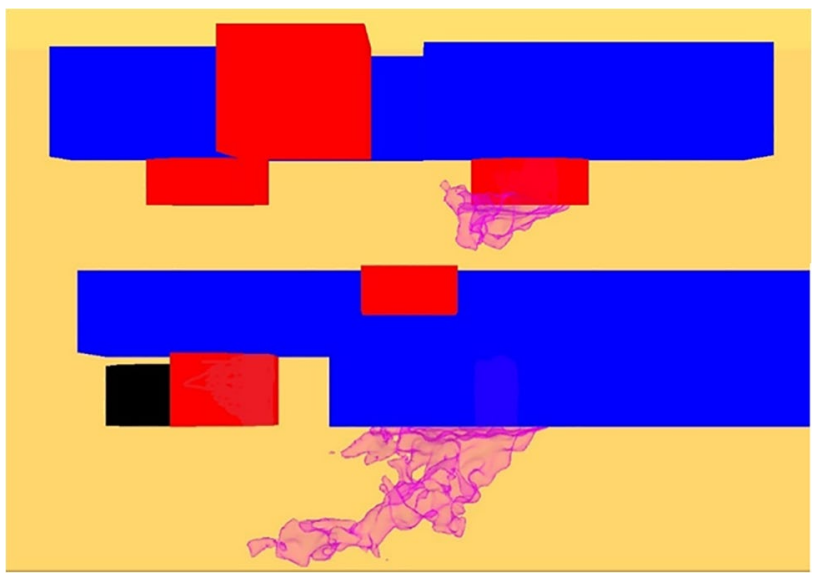

Fig. 19 The distribution of the isosurface $\left(300{ }^{\circ} \mathrm{C}\right)$ in the xy-plane of the drilling rig (top) and the loader (bottom), $2.0 \mathrm{~m} / \mathrm{s}$ flow velocity

\subsubsection{Velocity Distribution}

When studying the velocity distribution in parallel to the ventilation flow, it was found that the velocities at the underside of the vehicle were generally higher in the loader simulations compared to the drilling rig simulations. Following upon this, the front mudguard and tyre of the loader are exposed to higher flow velocities compared to the drilling rig. In the loader simulations, a larger area with higher velocities can be found between the rear wheelhouse and front mudguard. This is due to the lower flame tilt angle of the loader simulations, where a large portion of flames and fire gases with higher velocities will be found in between the tyres. When studying the velocity distribution from above, similar observations were made as for the temperature distribution, i.e. fire gases with higher velocities veered in towards the vehicle body in the drilling rig case and the fire gases in the loader case mostly followed the ventilation flow.

\section{Conclusions}

An in-depth analysis of tyre fires on mining vehicles was presented. Data from full-scale fire experiments and CFD simulations were applied in the analysis.

The wheelhouse of the loader was found to cause an increase in the flame tilt angle of approximately $10 \%$ when comparing with the calculated free burning case, decreasing the risk of flame impingement and heat flux downstream. Applying experimental data, the flame temperature of the drilling rig tyre was found to be approximately $7 \%$ higher than the loader tyre, increasing the risk of igniting adjacent fuel items. The lower flame temperature of the loader tyre was most likely due to an increased soot formation, depending on a different tyre material composition. The 
construction of the wheelhouse/mudguard will contribute to a longer flame length by creating a fuel-rich environment and reducing the entrainment rate. The wheelhouse/mudguard construction was found to have a larger impact on the flame length than the increased entrainment rate caused by the chimney effect and the Venturi effect. A longer flame length would increase the risk of flame impingement, higher incident heat flux on fuel surfaces and thus the ignition of adjacent fuel items.

Incident heat flux values (from flame radiation) as a function of the distance from a burning tyre were calculated. The resulting heat flux values could be applied in conjunction with critical heat fluxes of materials typically found in underground mines and on mining vehicles, when analysing safety distances to decrease the risk of ignition from a tyre fire.

Thermocouples in the inner part of the wheel/tyre section of the drilling rig measured temperatures exceeding $800{ }^{\circ} \mathrm{C}$ $10 \mathrm{~min}$ after the initiation of the experiment. Any combustible material exposed to the hot fire gas flow will most likely ignite at an early stage, emphasizing any shielding measures to prevent or at least delay the ignition.

The CFD simulations predicted higher flame tilt angles for the drilling rig case for higher flow velocities, indicating the influence of a varying wheelhouse/mudguard construction on the flame tilt angle but also the influence of the geometry of the tyre. A larger tyre width will increase the amount of pyrolysis products flowing out of the wheelhouse, decreasing the flow velocity, whereas a larger tyre diameter would decrease the influence of the outflow of pyrolysis products.

It was found that fire gases with higher temperatures could be seen in the lower parts downstream of the fire to a larger degree in the loader simulations compared to the drilling rig. This could partially be explained by fire gases and flames escaping at the lower level towards the front tyre and mudguard as well as along the underside of the vehicle. The decreased ventilation capability of the loader wheelhouse was caused by the higher heat release rate and smoke production in the loader case.

The construction of the loader resulted in a flow behaviour, where the short distance to the front mudguard/tyre and the separation of flow directly downstream of the protruding construction led to the flow of flames and fire gases being largely steered past the front mudguard/tyre, whereas in the case of the drilling rig, the longer distance to the front mudguard/tyre led to the flow of fire gases being directed towards the body of the vehicle after passing the area with flow separation. The simulated result was validated by documentation from full-scale fire experiments.

The influencing parameters on the fire behaviour and impact of burning tyres in a mine drift are numerous, where phenomena will work in different directions with respect to risks, adding to the complexity.
Acknowledgements The author would like to thank and acknowledge the support from the Sustainable Minerals Institute, The University of Queensland.

Funding Open Access funding enabled and organized by CAUL and its Member Institutions.

Data Availability Available upon request.

Code Availability Available upon request.

\section{Declarations}

Conflict of Interest The author declares no competing interests.

Open Access This article is licensed under a Creative Commons Attribution 4.0 International License, which permits use, sharing, adaptation, distribution and reproduction in any medium or format, as long as you give appropriate credit to the original author(s) and the source, provide a link to the Creative Commons licence, and indicate if changes were made. The images or other third party material in this article are included in the article's Creative Commons licence, unless indicated otherwise in a credit line to the material. If material is not included in the article's Creative Commons licence and your intended use is not permitted by statutory regulation or exceeds the permitted use, you will need to obtain permission directly from the copyright holder. To view a copy of this licence, visit http://creativecommons. org/licenses/by/4.0/.

\section{References}

1. De Rosa M.I. (2004), Analysis of mine fires for all US metal/ non-metal mining categories, 1990-2001. NIOSH.

2. Hansen R (2018) Fire statistics from the mining industry in New South Wales, Queensland and Western Australia. The University of Queensland, Brisbane

3. Hansen R (2021) The passive fire protection of mining vehicles in underground hard rock mines. Mining, Metallurgy \& Exploration 38:609-622

4. Welker JR, Sliepcevich CM (1966) Bending of wind-blown flames from liquid pools. Fire Technol 2:127-135

5. Moorhouse J. Scaling criteria for pool fires derived from largescale experiments. I Chem E Symp Ser 1982:507-24.

6. Johnson AD (1993) A model for predicting thermal radiation hazards from large-scale LNG pool fires. I Chem E Symp Ser 130:507-524

7. Oka Y, Atkinson GT (1995) Control of smoke flow in tunnel fires. Fire Saf J 25:305-322

8. Lee YP, Tsai KC (2012) Effect of vehicular blockage on critical ventilation velocity and tunnel fire behavior in longitudinally ventilated tunnels. Fire Saf J 53:35-42

9. F. Chaabat, M. Creyssels, A. Mos, J. Wingrave, H. Correia, M. Marro, P. Salizzoni (2019). The effects of solid barriers and blocks on the propagation of smoke within longitudinally ventilated tunnels. Building and Environment, vol 160.

10. Wu Y, Xing HJ, Atkinson G (2000) Interaction of fire plume with inclined surface. Fire Saf J 35:391-403

11. Smith DA (1992) Measurements of flame length and flame angle in an inclined trench. Fire Safety J 18:231-244

12. $\mathrm{Wu}$ Y, Drysdale DD. Upward flame spread on inclined surfaces. HSE Contract 2527/R04.25, February 1996. 
13. Kurioka H, Oka Y, Satoh H, Sugawa O (2003) Fire properties in near field of square fire source with longitudinal ventilation in tunnels. Fire Saf J 38:319-340

14. Oka Y., Kurioka H., Satoh H., Sugawa O. (1999). Modelling of unconfined flame tilt in cross-winds. Fire Safety Science - Proceedings of the Sixth International Symposium, pp 1161-1112, Poitiers, France.

15. Oka Y, Kurioka H (2006) Effect of shape and size of a fire source on fire properties in vicinity of a fire source in a tunnel. Fire Science and Technology 25:15-29

16. Li YZ, Ingason H. Maximum ceiling temperature in a tunnel fire. SP Report 2010:51, Borås: SP Swedish National Testing and Research Institute; 2010.

17. Rew C. and Deaves D. (1999). Fire spread and flame length in ventilated tunnels - a model used in channel tunnel assesments. In: Proceedings of the International Conference on Tunnel Fires and Escape from Tunnels. Lyon, France, pp 397-406.

18. Ingason $\mathrm{H}, \mathrm{Li} \mathrm{YZ}$ (2010) Model scale tunnel fire tests with longitudinal ventilation. Fire Saf J 45:371-384

19. Hansen R (2019) Fire behaviour of multiple fires in a mine drift with longitudinal ventilation. Int J Min Sci Technol 29:245-254

20. Johnsson E, Yang JC (2014) Experimental study on tyre fire penetration into a motorcoach passenger compartment. Fire Mater 38:63-76

21. Wraight H. (1969). The ignition of motor tyre samples. Fire research note no 742, Fire Research Station, Borehamwood.

22. Shipp MP., Guy PS. (1993). Fire behaviour of rubber tyres. Fire Research Station report TCR 65/93, Building Research Establishment.

23. Hansen PA. (1995). Fires in tyres - heat release rate and response of vehicles. SINTEF - Norwegian Fire Research Laboratory.

24. Ingason H, Hammarström R. (2010). Fire test with a front wheel loader rubber tyre. SP report 2010:64, SP Technical Research Institute of Sweden, Borås

25. Hansen R (2015) Analysis of methodologies for calculating the heat release rates of mining vehicle fires in underground mines. Fire Saf J 71:194-216

26. Hansen R, Ingason H. Full scale fire experiments with mining vehicles in an underground mine. Research report SiST 2013:2. Västerås: Mälardalen University; 2013.
27. McGrattan K, Hostikka S, Floyd J, McDermott R and Vanella M. Fire dynamics simulator, user's guide (NIST Special Publication 1019, Sixth Edition). Gaithersburg: NIST, 2020.

28. Hansen R (2020) Modelling temperature distributions and flow conditions of fires in an underground mine drift. Geosyst Eng 23:299-314

29. Ingason H. Fire test with a front loader. SP Report P801596; 2008

30. Baum H.R. and McCaffrey B.J. (1989). Fire induced flow field theory and experiment. In: Proceedings of the $2^{\text {nd }}$ International Symposium - Fire Safety Science. Tokyo, Japan, pp 129-148.

31. Ingason $H$ (1994) Two dimensional rack storage fires. Proceedings from the $4^{\text {th }}$ International Symposium - Fire Safety Science. Canada, Ottawa, pp 1209-1220

32. Cox G, Chitty R (1980) A study of the deterministic properties of unbounded fire plumes. Combust Flame 39:191-209

33. Audouin L, Kolb G, Torero JL, Most JM (1995) Average centerline temperatures of a buoyant pool fire obtained by image processing of video recordings. Fire Saf J 24:167-187

34. Hottel HC. (1931). Radiant heat transmission between surfaces separated by non-absorbing media. Trans. ASME, vol 53, FSP53-196, pp 265-273.

35. Howell JR, Siegel R, Pinar MM (2011) Thermal radiation heat transfer -, 5th edn. CRC Press, Boca Raton, Florida

36. Babrauskas V (2003) Ignition handbook. Fire Science Publishers, Issaquah

37. Harper CA (2004) Handbook of materials for fire protection. McGraw-Hill, New York

38. Janowska G, Kucharska-Jastrząbek A, Rybiński P, Wesołek D, Wójlik I (2010) Flammability of diene rubbers. J Therm Anal Calorim 102:1043-1049

Publisher's Note Springer Nature remains neutral with regard to jurisdictional claims in published maps and institutional affiliations. 